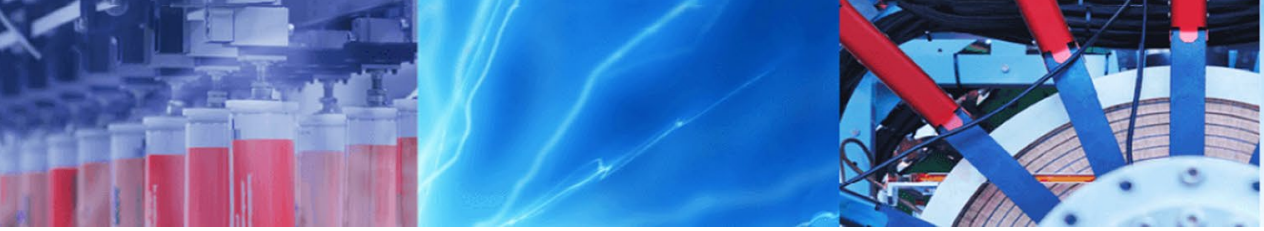

Research Article

\title{
Impact assessment of socioeconomic factors on dimensions of environmental degradation in Pakistan
}

\author{
Sohail Abbas ${ }^{1}$ (D) Shazia Kousar ${ }^{2} \cdot$ Muhammad Yaseen $^{3} \cdot$ Zulfiqar Ali Mayo $^{4} \cdot$ Memoona Zainab $^{5}$. \\ Muhammad Junaid Mahmood ${ }^{3} \cdot$ Hassan Raza $^{6}$
}

Received: 5 December 2019 / Accepted: 10 February 2020 / Published online: 22 February 2020

(c) Springer Nature Switzerland AG 2020

\begin{abstract}
Environmental degradation is a natural and socioeconomic cause-effect phenomenon that is widespread all over the world. The current study investigates the impact of socioeconomic factors on dimensions of environmental degradation in Pakistan for the period of 1984 to 2017. The impact of socioeconomic factors on dimensions of environmental degradation is investigated using the augmented Dicky-Fuller unit root test and the autoregressive distributed lag bounds test. The cumulative sum of recursive residuals and the cumulative square sum of recursive residuals were used to check the stability of the socioeconomic parameters on dimensions of environmental degradation of three investigated models. The study observed a negative and significant impact on environmental degradation in all three models. The analysis incorporated that FDI, per capita GDP, industrialization and the total population have a positive and significant effect on environmental degradation in the long run; as FDI, per capita GDP and total population increase, this will cause environmental degradation to increase. The rural population and agricultural land have an insignificant association with environmental degradation. The present study also indicates that dimensions of the environmental degradation in Pakistan are mostly influenced by the governance. However, this research will help the policy makers to understand the importance of the governance and environmental degradation.
\end{abstract}

Keywords Governance $\cdot \mathrm{CO}_{2}$ emission $\cdot \mathrm{NO}_{x}$ emission · Deforestation · Pakistan

\section{Introduction}

Environmental degradation is one of the severe challenges of this time. The word environmental relatively often tends to be related to a particular kind of human impact on the biosphere with the natural system. This circumstance differentiates it from the word ecology which can be categorized as a conception of the interdependence within an ecosystem [1]. Environmental degradation is a big problem not only for local areas, but for the whole planet on a global scale. When the pollutants accumulate in our atmosphere, it creates the concept of the greenhouse effect. It is the basic cause of the global warming. Such high scale warming affects wind and sea water circulation patterns globally, but also directly or indirectly effects local climatic conditions with changes in the patterns of precipitation and temperature. As the global temperature increases, the arctic ice melts more rapidly that increases the sea level $[2,3]$. There are particularly five indicators of environmental degradation: Greenhouse gas emission, air contamination, water contamination, deforestation and land degradation that directly damage the environment through human actions [4]. Environmental degradation like land degradation, $\mathrm{CO}_{2}, \mathrm{NO}_{x}$, water pollution and soil

$\triangle$ Sohail Abbas, sohail.konkuk@gmail.com | ${ }^{1}$ Climate Research Institute, Konkuk University, Seoul, South Korea. ${ }^{2}$ Institute of Management Sciences, Superior University Lahore, Lahore, Pakistan. ${ }^{3}$ Center for Integrated Mountain Research (CIMR), University of the Punjab, Lahore, Pakistan. ${ }^{4}$ Agricultural Statistical Officer, Punjab Agriculture Department, Lahore, Pakistan. ${ }^{5}$ Institute of Management Sciences, University of South Asia, Lahore, Pakistan. ${ }^{6}$ Institute of Environmental Engineering and Sciences (LESE), NUST, Islamabad, Pakistan. 
erosion is an outcome of poor governance and lack of monitoring of the rules and regulation $[2,5,6]$.

Pakistan potentially faces a substantial climate change challenge [7]. During the previous 50 years, typically the annual mean temperature inside Pakistan has increased by around $0.5^{\circ} \mathrm{C}$ [8]. Usually, the amount of heat absorption trend in days and nights has grown nearly five times in the previous 3 decades. However, the temperature in Pakistan is usually likely to rise by 3 to $5^{\circ} \mathrm{C}$ relating to a global warming scenario $[9,10]$. This increasing temperature has influence on different industries which include water availability, plant growth, forests, biodiversity conservation and animals. Pakistan lies among the developing countries around the world with a $5.79 \%$ gross domestic product growth and per household earnings around \$1641 [11, 12]. Large areas of Pakistan experience high heat index, resulting in the reduction in agricultural yield, environmental deterioration and the reduction in forest covered area. The heat index is a threat to the green sector in all Pakistan like Southern Punjab, Southeastern Baluchistan and almost covered all areas of Sindh also extending up to north eastern Baluchistan in Pakistan [13].

In the context of the environmental degradation, Pakistan is facing the ecological degradation problems. With the greater heat trapped in the earth's surface, the $\mathrm{CO}_{2}$ emissions reached till $1 \%$ of the total planet emissions. Pakistan's metropolitan wind streams contaminants which are probably the most severe in the world. The contamination directly affects the activities on the ecosystem and creates the social disharmony and economic instability. The regular level of contaminants in huge metropolitan communities of Pakistan is approximately four times higher than that of the World Health Organization limits [14]. The primary reason for air contamination is $\mathrm{NO}_{x}$. Basically, the $\mathrm{NO}_{x}$ is an expression used to describe two types of oxides of nitrogen: nitric oxide (NO) and nitrogen dioxide $\left(\mathrm{NO}_{2}\right)$. The primary nitrogen oxides discharged from vehicles.

The deforestation is the other factor of the environmental degradation. The forest cover in Pakistan remains lower than $2.23 \%$ of total land $[15,16]$. The major outcome of the deforestation is the biodiversity loss. The habitat conservation is very important for the stemming this loss. The reduction in the forest area resulted in the reduction in the woody biomass. It shows the long-term relationship with the environmental degradation and social disharmony [17, 18]. The association between environmental degradation and socioeconomic factors becomes the major issue and becomes the focal point of research. Generally, there are three main schools of thought in relation to the causal relationship between FDI, GDP, economic growth and environmental degradation. The first thought is related to the empirical studies which tested the validity of the environmental Kuznets curve (EKC) hypothesis. The second school of thought is the examination focused on the relationship between socioeconomic factors and environmental degradation. The final stream is the examination of the hypothesis that there is a fundamental relationship between industrialization and GDP that is represented by FDI flows and $\mathrm{CO}_{2}$ emissions [19-21]. The linkage between environmental degradation and economic growth is directly affected by governance $[22,6]$.

There are many researchers in the worldwide who studied $\mathrm{CO}_{2}, \mathrm{NO}_{x}$ and DEF, GDP, FDI, governance and population growth $[23,24]$. Researchers claimed that trend of $\mathrm{CO}_{2}$ emissions varies in developed and developing countries. The increase in GDP is the source of the of $\mathrm{CO}_{2}$ emissions in a poor country, but in the case of developed countries the pollution tends to decrease due to good governance and increase in income level [25]. Chen and Huang [26] described the link between $\mathrm{NO}_{x}$ emission and economic growth; the study claimed the long-run relationship between GDP, FDI, energy use and $\mathrm{CO}_{2}$ emissions. Cohen et al. [27] also reported the trend relationship between emissions and GDP from the cyclical connection. Meyer et al. [28] stated that deforestation and GDP have the negative relationship within a cyclic way.

The governance is a multidimensional concept and consists of six dimensions like voice and accountability, political stability, government effectiveness, regulatory quality, rules of law and control of corruption [29]. The definition and measurement of governance are given in "Appendix". The governance plays important role to define business environment, economic security and policies for foreign direct investment within the country. Moreover, international agencies have right to comment and rank each country's governance situation and allocate a score and rank on the basis of six dimensions of governance annually. The industrial revolution brought explicit changes in the society of England, European continents first and later it affected the developing nations. The invention of the steam engine and use of coal as a primary source of energy leads the industrial revolution. Huge industrial development kept the foundation of urbanization by creating opportunities of employment and higher wages. Nowadays, expansion of the industrial sector and urbanization started to affect the quality of the environment, especially in developing nations where due to lack of governance and use of conventional technology, emission of greenhouse gases significantly contributes to environmental degradation. The $\mathrm{CO}_{2}$ emission, $\mathrm{NO}$ emission and Deforestation are the basic indicators of the environmental degradation [30, 31].

Good governance and well-integrated policy responses help to minimize the environmental degradation challenges. In developing nations, government policies and 
decision about the business environment and foreign direct investment affect environment quality [32]. For instance, Michael Kugelman, deputy director and senior associate for South Asia with the Woodrow Wilson Center's Asia Program, showed deep concerns about the environmental impacts of China Pakistan Economic Corridor (CPEC) in Pakistan. Similarly, government policies regarding irrigation system and industrialization affect water resource and air quality. Therefore, environment quality is not only determined by the capacities of environmental authorities, but other external factors (enabling environment) are also a key determinant of environment degradation.

An improved political institution attracts foreign direct investment which helps the economy to uplift, but at the same time it contributes toward the environmental performance [33]. Thus, only the powerful legislation, successful enforcement of law and provision of improved public services save the economy form excessive emissions of $\mathrm{CO}_{2}$ and NO [34]. However, the aim of this study is to develop a link between two complex concepts governance and environment degradation; whereas environment degradation indicates depletion of air, water and soil resources or undesirable changes to the environment, governance means actions or manners of governing a state. The specific objectives are included to estimate the impact of governance on determinants of environmental degradation and some other variables such as foreign direct investment, industrialization, transportation, population, urbanization, and agricultural land.

\section{Materials and methods}

\subsection{Data}

The effect of governance on environmental degradation was investigated hypothetically. Particularly, three models are formed to evaluate and assess the connected hypothesis with dependent and independent variables. The $\mathrm{CO}_{2}$ emission, $\mathrm{NO}_{x}$ emission and deforestation were taken as the dependent variables, while the governance, foreign direct investment, gross domestic product per capita, industrialization, transportations, urbanization, population growth and agriculture land were taken as independent variables. The investigated span consists of the 33 years from 1984 to 2017. The data were obtained from the World Development Indicators (WDI) and International Country Risk Guide (ICRG).

\subsection{Econometric models}

In order to keep the main focus and to investigate the effect of governance on environmental degradation dimensions, the specific three outputs and input functions (models) are included in the study.

\subsubsection{Model 1}

Output and input function used for $\mathrm{CO}_{2}$ emission is as follows:

$\mathrm{CO}_{2}=\beta_{0}+\beta_{1} \mathrm{Gov}+\beta_{2} \mathrm{FDI}+\beta_{3} \mathrm{GDP}+\beta_{4} \mathrm{Pop}+\beta_{5} \mathrm{Indu}+\mu$

\subsubsection{Model 2}

Output and input function used for $\mathrm{NO}_{x}$ emission is as follows:

$$
\begin{aligned}
\mathrm{NO}_{x}= & \beta_{0}+\beta_{1} \mathrm{Gov}+\beta_{2} \operatorname{Tran}+\beta_{3} \mathrm{GDP} \\
& +\beta_{4} \mathrm{Pop}+\beta_{5} \mathrm{FDI}+\beta_{6} \operatorname{Indu}+\mu
\end{aligned}
$$

\subsubsection{Model 3}

Output and input function used for DEF (deforestation) is as follows:

$\mathrm{DEF}=\beta_{0}+\beta_{1} \mathrm{Gov}+\beta_{2} \mathrm{Indu}+\beta_{3} \mathrm{FDI}+\beta_{4} \mathrm{Pop}+\beta_{5} \mathrm{Urbn}+\beta_{6} \mathrm{AL}+\mu$

where $\mathrm{CO}_{2}, \mathrm{NO}_{x}$ and DEF are total carbon dioxide emissions (metric tons per capita), nitrous oxide emissions and total deforestation of Pakistan. The Gov is the governance with the range 0 to 1 . FDI and GDP are the total foreign direct investment and gross domestic product per capita, respectively. Pop and Indu are the population growth rate and industrial GDP at current factor cost, respectively. Tran and Urbn are the total transportation and urban, respectively. $\mathrm{AL}$ is the agricultural land. $\mu$ is the error term.

\subsection{Experimental investigation}

In the current research, an investigation of the impact assessment of socioeconomic factors on dimensions of environmental degradation in Pakistan has been made using the statistical techniques. The broadened Dickey larger method was used to gather data. The autoregressive distributed lag model (ARDL) bond test approach (2001) was used to check the relationship between dependent and independent variables for longer-run time series. The experimental investigation procedure conducted in this study follows four steps. 
Step 1: To check the stationary of data, the unit root test has been used. Unit root test investigates the stationarity of time series data. In statistics, a unit root test is reliable either time series variable is non-stationary and possesses a unit root. It is also known as a difference stationary process. This test creates a stationary series of observations. The null hypothesis of augmented Dicky-Fuller (ADF) unit root the presence of a unit root and the alternative hypothesis is no unit root. Data will be considered as stationary if it possesses zero mean, constant variance and covariance, and non-stationary if it has an unpredictable mean as compared to a nonzero mean. Stationary time series produce more reliable results, hence reliable for policy makers.

Step 2: Augmented Dickey Fuller (ADF) test was used to examine the sequential relationship associated with the data [31]. The test continues to be continued running upon mis-step terms making use of the second demand slacked subordinate variable. The invalid hypotheses convey that there will be no serial partnership in the data option of stationarity within the data. The heading with the condition has been shown in ADF test equation in each model.

$$
\begin{aligned}
& \mathrm{CO}_{2}=\alpha_{0}+\alpha_{1} \mathrm{CO}_{2-1}+\sum_{k=1}^{\rho} \varphi_{k} \Delta \mathrm{CO}_{2-k}+\epsilon_{1} \\
& \mathrm{NO}_{x}=\beta_{0}+\beta_{1} \mathrm{NO}_{x-1}+\sum_{k=1}^{\rho} \emptyset_{k} \Delta \mathrm{NO}_{x-k}+\epsilon_{2} \\
& \mathrm{DEF}=\gamma_{0}+\gamma_{1} \mathrm{DEF}_{-1}+\sum_{k=1}^{\rho} \theta_{k} \Delta \mathrm{DEF}_{-k}+\epsilon_{3}
\end{aligned}
$$

Here, $\mathrm{CO}_{2}, \mathrm{NO}_{x}$ and DEF are the dependent variables and $\epsilon_{1}, \epsilon_{2}$ and $\epsilon_{3}$ are the mistake terms. $\mathrm{CO}_{2-1}, \mathrm{NO}_{x-1}$ and $\mathrm{DEF}_{-1}$ indicate slacked subordinate variable. The model outcomes in information serially uncorrelated, which implies that no serial relationship between dependent variables and independent variables.

Step 3: Environmental degradation indicators $\left(\mathrm{CO}_{2}\right.$ emission, $\mathrm{NO}_{\mathrm{x}}$ emission, Deforestation) taken as dependent variables and socio-economic indicators like governance, foreign direct investment, gross domestic product per capita, industrialization, transportations, urbanization, population growth and agriculture land as independent variables in the estimated models. In order to check the high order lagged dependent variables, this study used the bound test. The null hypothesis states that there is no long-term relationship between dependent and explanatory variables alternative to long-term relationship of variables [31,35]. The estimates of the models show a rejection of our null hypothesis stating that there is a long-term relationship between governance as an explanatory variable with environmental degradation of the county, since the $F$-calculated value is greater than the $F$-tabulated value. The lagged variables were further employed in the model using the Akaike Information and Schwartz Bayesian criterion. ARDL model equations estimated for our model are given as follows:

ARDL equation for output and input function used for $\mathrm{CO}_{2}$ emission

$$
\begin{aligned}
& \mathrm{CO}_{2}=\alpha_{0}+\sum_{i=1}^{N} \alpha_{1} \Delta \mathrm{CO}_{2-i}+\sum_{i=0}^{N} \alpha_{2} \Delta \mathrm{Gov}_{-i}+\sum_{i=0}^{N} \alpha_{3} \Delta \mathrm{FDI}_{-i} \\
& +\sum_{i=0}^{N} \alpha_{4} \Delta \mathrm{GDP}_{-i}+\sum_{i=0}^{N} \alpha_{5} \Delta \mathrm{Pop}_{-i}+\sum_{i=0}^{N} \alpha_{6} \Delta \mathrm{Indu}_{-i} \\
& +\alpha_{7} \mathrm{CO}_{2-1}+\alpha_{8} \mathrm{Gov}_{-1}+\alpha_{9} \mathrm{FDI}_{-1} \\
& +\alpha_{10} \text { GDP }_{-1}+\alpha_{11} \text { Pop }_{-1}+\alpha_{12} \text { Indu }_{-1}+\mu 1
\end{aligned}
$$

$A R D L$ equation for output and input function used for $\mathrm{NO}_{x}$ emission

$$
\begin{aligned}
\mathrm{NO}_{x}= & \beta_{0}+\sum_{i=1}^{N} \beta_{1} \Delta \mathrm{NO}_{x-i}+\sum_{i=0}^{N} \beta_{2} \Delta \mathrm{Gov}_{-i}+\sum_{i=0}^{N} \beta_{3} \Delta \operatorname{Tran}_{-i} \\
& +\sum_{i=0}^{N} \beta_{4} \Delta \mathrm{GDP}_{-i}+\sum_{i=0}^{N} \beta_{5} \Delta \mathrm{Pop}_{-i}+\sum_{i=0}^{N} \beta_{6} \Delta \mathrm{FDI}_{-i} \\
& +\sum_{i=0}^{N} \beta_{7} \mathrm{Indu}_{-i}+\beta_{8} \mathrm{NO}_{x-1}+\beta_{9} \mathrm{Gov}_{-1}+\beta_{10} \mathrm{Tran}_{-1} \\
& +\beta_{11} \mathrm{GDP}_{-1}+\beta_{12} \mathrm{Pop}_{-1}+\beta_{13} \mathrm{FDI}_{-i}+\beta_{14} \mathrm{Indu}_{-1}+\mu 2
\end{aligned}
$$

$A R D L$ equation for output and input function used for $D E F$ (deforestation)

$$
\begin{aligned}
\mathrm{DEF}= & \gamma_{0}+\sum_{i=1}^{N} \gamma_{1} \Delta \mathrm{DEF}_{-i}+\sum_{i=0}^{N} \gamma_{2} \Delta \mathrm{Gov}_{-i}+\sum_{i=0}^{N} \gamma_{3} \Delta \mathrm{Indu}_{-i} \\
& +\sum_{i=0}^{N} \gamma_{4} \Delta \mathrm{FDI}+\sum_{i=0}^{N} \gamma_{5} \Delta \mathrm{Pop}_{-i}+\sum_{i=0}^{N} \gamma_{6} \Delta \mathrm{Urbn}_{-i} \\
& +\sum_{i=0}^{N} \gamma_{7} \Delta \mathrm{AL}_{-i}+\gamma_{8} \mathrm{DEF}_{-1}+\gamma_{9} \mathrm{Gov}_{-1}+\gamma_{10} \mathrm{Indu}_{-1} \\
& +\gamma_{11} \mathrm{FDI}_{-1}+\gamma_{12} \mathrm{Pop}_{-1}+\gamma_{13} \mathrm{Urbn}_{-1}+\gamma_{14} \beta_{7} \mathrm{AL}_{-1}+\mu 3_{t}
\end{aligned}
$$

In this autoregressive distributed lag model, $a$ denotes the short-term coefficient, $\beta$ denotes the long-term coefficient, and maximum lag length is denoted by $N$.

Step 4: The stability test is used. The combined sum of recursive residual (CUSUM) and cumulative sum of square of recursive residual (CUSUM square) are given to examine the long operate and short operate security from the partnership, separately. In previous 
examinations, these types of tests were used to check the protection of the design. This test continues to be utilized as a percentage of strength in our model $[36,37]$.

\section{Results and discussion}

\subsection{Empirical analysis}

The significance of the all dependent and independent variables has been investigated using the empirical analysis of the models. The long-run and the short-run relationships between dependent and independent variables are investigated using the ARDL cointegration test. After that, a diagnostic test was used to check the data normality. The stability test was also used for the investigation of the stable model. The empirical analysis included: unit root test, ARDL bound testing, Breusch-Godfrey serial correlation LM test, heteroscedasticity and stability test.

\subsubsection{Unit root test}

The unit root test investigates whether time series data are constant/stationary. Without stationary, the empirical analysis shows the results would be ambiguous. A stationary series is characterized as a series that tends to come back to its mean value and fluctuate round it within a consistent range, while a non-stationary series is characterized as a series, its value varies time to time, place to place and region to region, and its variance increases with the sample size [38]. Therefore, to investigate the statistical stationarity of time series data is very important to find out the most reliable results, while the non-stationary time series shows only time-varying mean or variance. If the time series is assimilated and unified at the order 0 , then this is called stationary. In other ways, if the time series is at order 1, this is called non-stationary. Figure $1 \mathrm{a}$, $b$ represents the results of unit root tests for all dependent and independent variables at the level and first difference value. If the absolute value of the ADF test is smaller than a certain value like $1 \%$ or $5 \%$ level of significance, then the null hypothesis cannot be reject. So, all the investigated variables in the all models are not observed in the 1 order. Some variables lie in the order 0 , and some in the 1 order. So, there is no unit root problem observed in investigating variables. $\mathrm{CO}_{2}, \mathrm{NO}_{x}, \mathrm{DEF}, \mathrm{GDP}$, Urbn and $\mathrm{AL}$ (Fig. $2 \mathrm{~b}$ ) are found to be stationary at level with intercept, while Tran, Gov, GDP, FDI, Pop and Indu (Fig. 2b) are stationary at the 1st difference with the intercept. From the detailed investigation, it is stated that some variables observed stationarity at level. While, others be measured stationary at 1 st differences. In this condition, the ARDL bound test approach would be used for cointegration.

\subsubsection{Bound test}

The autoregressive distributed lag (ARDL) test is used to estimate the long-run and short-run relationships in economic time series. Time series presents the long-run relationship. Thus, the bound test is implemented on the time series data. To estimate the impact of Governance and other socioeconomic parameters like foreign direct investment, Gross Domestic Product (GDP) per capita,
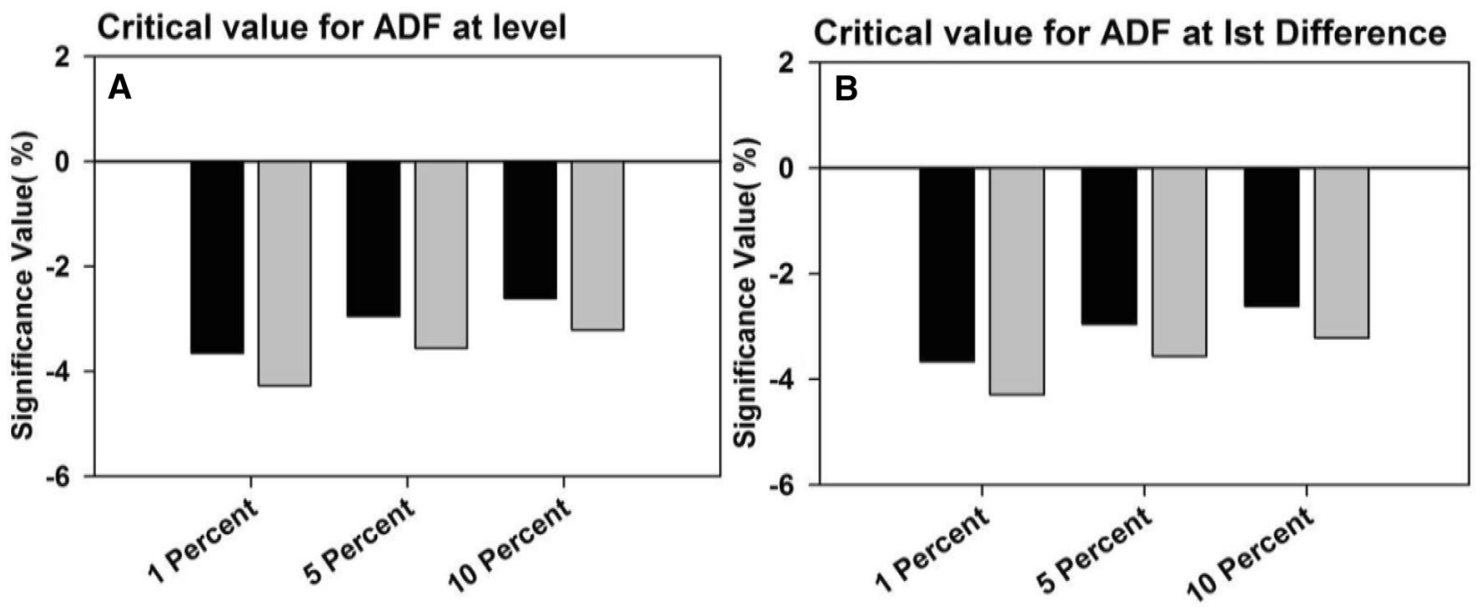

\section{$\square$ Intercept $\square$ Trend and Intercept}

Fig. 1 The critical values for Augmented Dickey Fuller (ADF) $\mathbf{a}$ at level and $\mathbf{b}$ first difference 

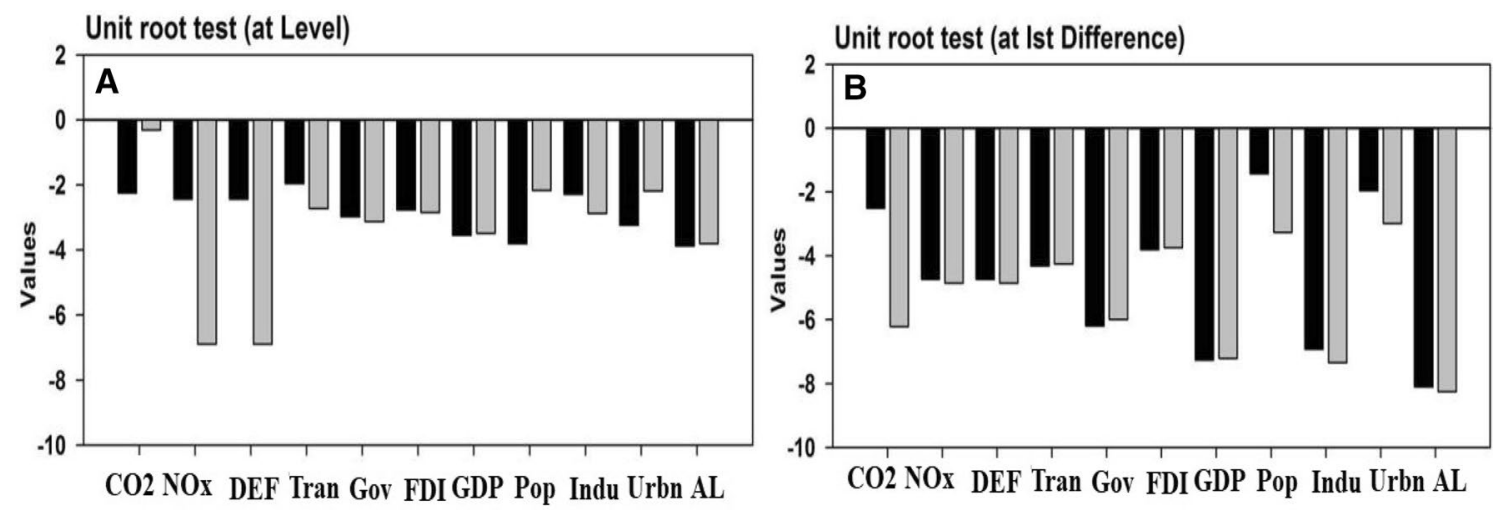

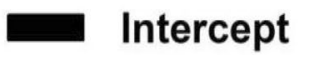

Fig. 2 The unit root test values $\mathbf{a}$ at level and $\mathbf{b}$ first difference

industrialization, transportations, urbanization, population growth and agriculture land environmental degradation parameters like $\mathrm{CO}_{2}$, emission, $\mathrm{NO}_{x}$ emission and deforestation (DEF). This input and out put function measured using the Bound test. Governance and other socioeconomic parameters like foreign direct investment, gross domestic product (GDP) per capita, industrialization, transportations, urbanization, population growth and agriculture land have been taken as the independent variables. The bound test investigates whether cointegration exists or not in the selected variables. If the relationship exists, then the null hypothesis is rejected. Figure $3 a$, b reveals that $F$ is very more important along with $95 \%$ conviction crack and $90 \%$ sureness interval; it rejects our null hypothesis that is $\mathrm{H}_{0}$ which shows that there is absolutely no long-term relationship among modeled variables in all three models and alternative hypothesis is like $\mathrm{H}_{1}$ that explains that there exists a long-term cointegration among the modeled variables. The results also show that $F$ value described the greater value than the upper bound value $10 \%$ and $5 \%$ for models 1,2 and 3 . However, the null hypothesis is rejected and the alternative hypothesis is accepted. Due to the rejection of the null hypothesis, cointegration is found between the investigated dependent and independent variables.
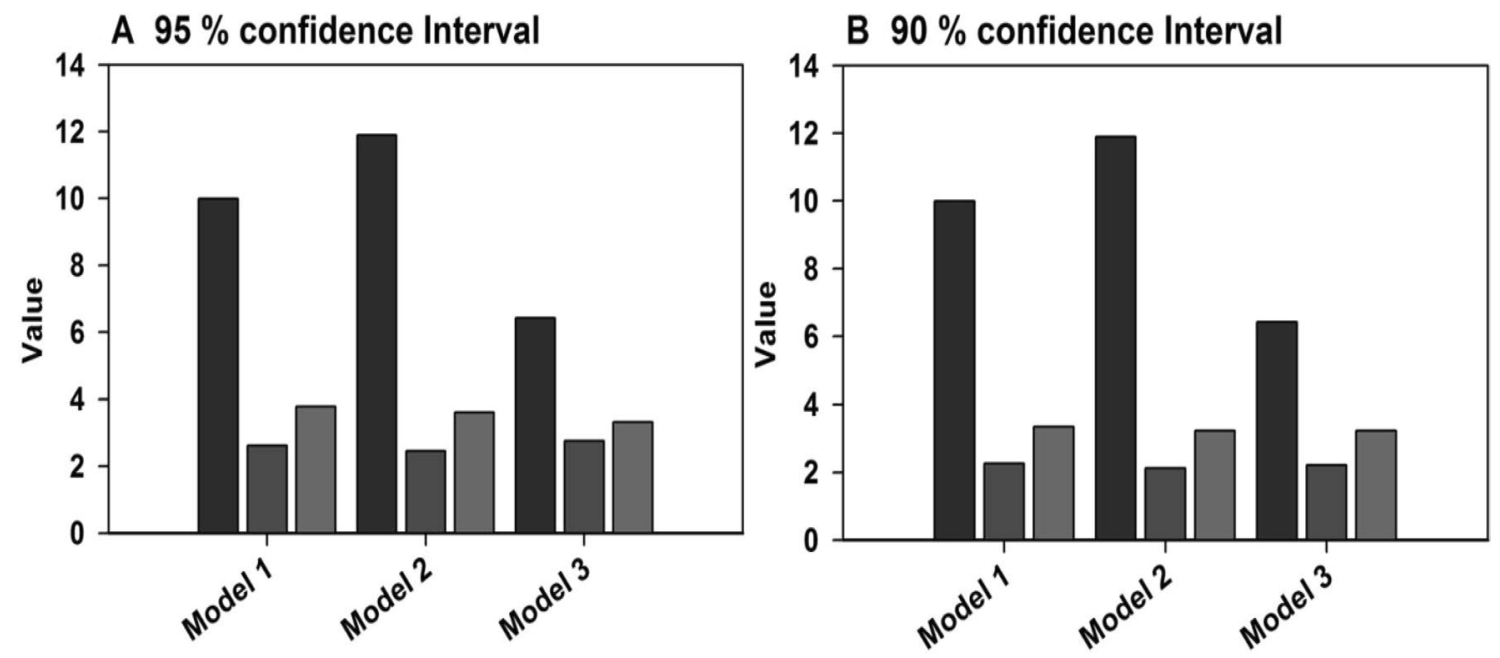

F value $\square$ Lower Limit

Upper Limit

Fig. 3 The bounds co integration test a 95 confidence interval and b 90 confidence interval 


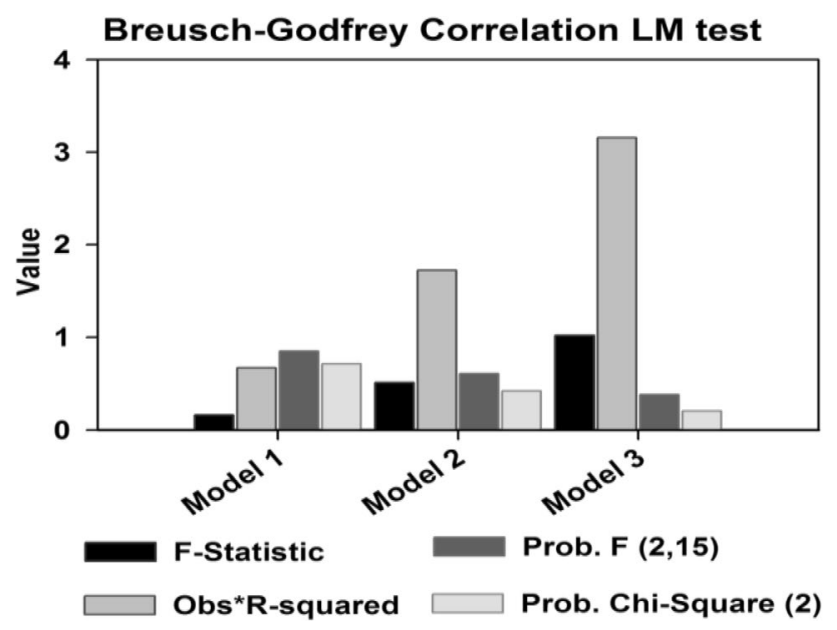

Fig. 4 The Breusch-Godfrey serial correlation LM test for models 1, 2 and 3

\subsubsection{Serial correlation}

The current investigation used the Breusch-Godfrey serial correlation LM test to check the autocorrelation in errors. The Breusch-Godfrey serial correlation LM test is used to find out the residuals from the model that has been considered for regression analysis. Therefore, this serial correlation LM test is used to measure the relationship between dependent and independent variables over a specific period of time in all models. The results depict that probability and chi-square value of test exceed from 5 and $10 \%$ level of significance (Fig. 4). It accepts the null hypothesis and rejects the alternative hypothesis. Therefore, no serial correlation for models 1, 2, 3 is observed during the investigation.

\subsubsection{Heteroscedasticity}

Heteroscedasticity is used to estimate the correlation coefficient in the reliability analysis of the models 1, 2 and 3. In order to perceive the heteroscedasticity, the Breusch-Pagan-Godfrey test is investigated. The Breusch-Pagan-Godfrey test is used to detect the heteroscedasticity of error in the regression. Heteroscedasticity means variance of error is increasing, but not equal, while homoscedasticity is important in regression analysis. If the assumption of homoscedasticity is not fulfilled, regression analysis can not be used. Therefore, this study used the Breusch-Pagan-Godfrey test to check the assumption of homoscedasticity with the null hypothesis. The results revealed that probe. Value is greater than 0.05 for all three models. It accepts the null hypothesis and rejects the alternative hypothesis which shows the homoscedasticity (Table 1).
Table 1 The Breusch-Pagan-Godfrey heteroscedasticity test

\begin{tabular}{lcll}
\hline Model 1 & & & \\
F-statistic value & 1.491855 & Prob. $F(14,17)$ & 0.2147 \\
${\text { Obser* } R^{2}}^{\text {Scaled explained SS }}$ & 17.64112 & Prob. chi-square (14) & 0.2236 \\
Model 2 & 4.581286 & Prob. chi-square (14) & 0.9908 \\
F-statistic value & 0.680853 & Prob. $F(14,17)$ & 0.7688 \\
Obser* $R^{2}$ & 12.46755 & Prob. chi-square (14) & 0.6433 \\
Scaled explained SS & 3.058424 & Prob. chi-square (14) & 0.995 \\
Model 3 & & & \\
F-statistic value & 1.001501 & Prob. $F(10,20)$ & 0.4744 \\
Obser* $R^{2}$ & 10.34367 & Prob. chi-square (14) & 0.4109 \\
Scaled explained SS & 2.804546 & Prob. chi-square (14) & 0.9857 \\
\hline
\end{tabular}

\subsubsection{Stability test}

This study used the CUSUM test for OLS residuals. It is based on the cumulative sum of the recursive residuals and the sum of square of residuals. This test is used to find instability between dependent and independent variables. If the plot of recursive residuals is between the standard error band, plus and minus two standard errors, the parameters of the OLS equations are stable, and if residuals are outside the standard error bands, it suggests instability in the parameters of the equation. The plot of both cumulative sum of recursive residual and cumulative sum of square of residual recursive for models 1, 2 and 3 lies between two critical lines (Figs. 5, 6, 7).

\subsection{Impact on $\mathrm{CO}_{2}$ emission}

\subsubsection{Descriptive statistics}

Table 2 depicts the descriptive statics values of the $\mathrm{CO}_{2}$ emission function. The results show that the probability value of all variables is greater than 0.05 , which indicated that the data are normally distributed. In the detailed examination, it states that the probability values of the selected variables were included: $\mathrm{CO}_{2}(0.321)$, the Gov (0.317), FDI (0.198), GDP (0.817), Pop (0.099) and Indu (0.401). The minimum values for $\mathrm{CO}_{2}(0.480)$, the Gov (0.271), FDI (0.178), GDP (-1.45), Pop (1.95) and Indu (17.94). The maximum value of the Indu is 25.52. The observed maximum values included: $\mathrm{CO}_{2}$ (0.99), the Gov (0.546), FDI (3.66), GDP (5.478), Pop (3.341) and Indu (25.52).

\subsubsection{Autoregressive distributed lag (ARDL) model: dependent variable is $\mathrm{CO}_{2}$ emission}

The results of ARDL for model 1 are reported in Table 3. The value of the error correction model term is $\beta=0.391(0.002)$, 

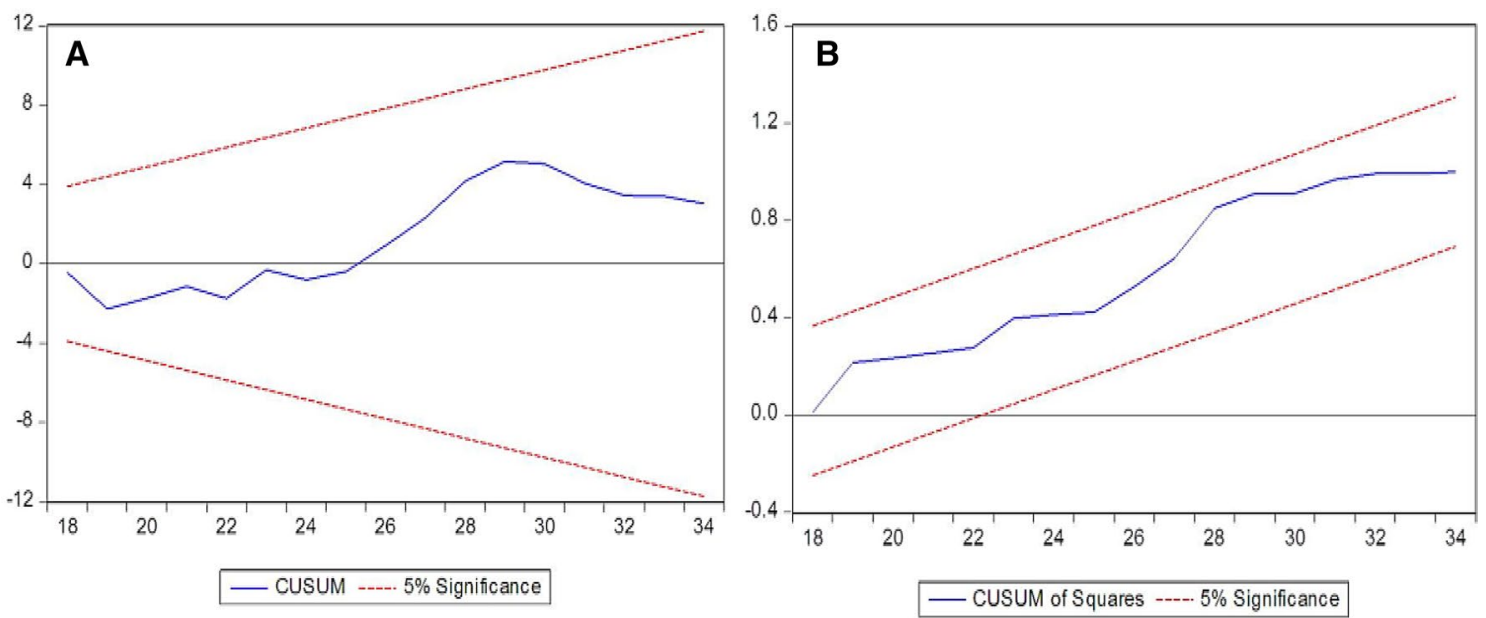

Fig. 5 a Cumulative sum of recursive residual and $\mathbf{b}$ cumulative sum of square of residual recursive (model 1)
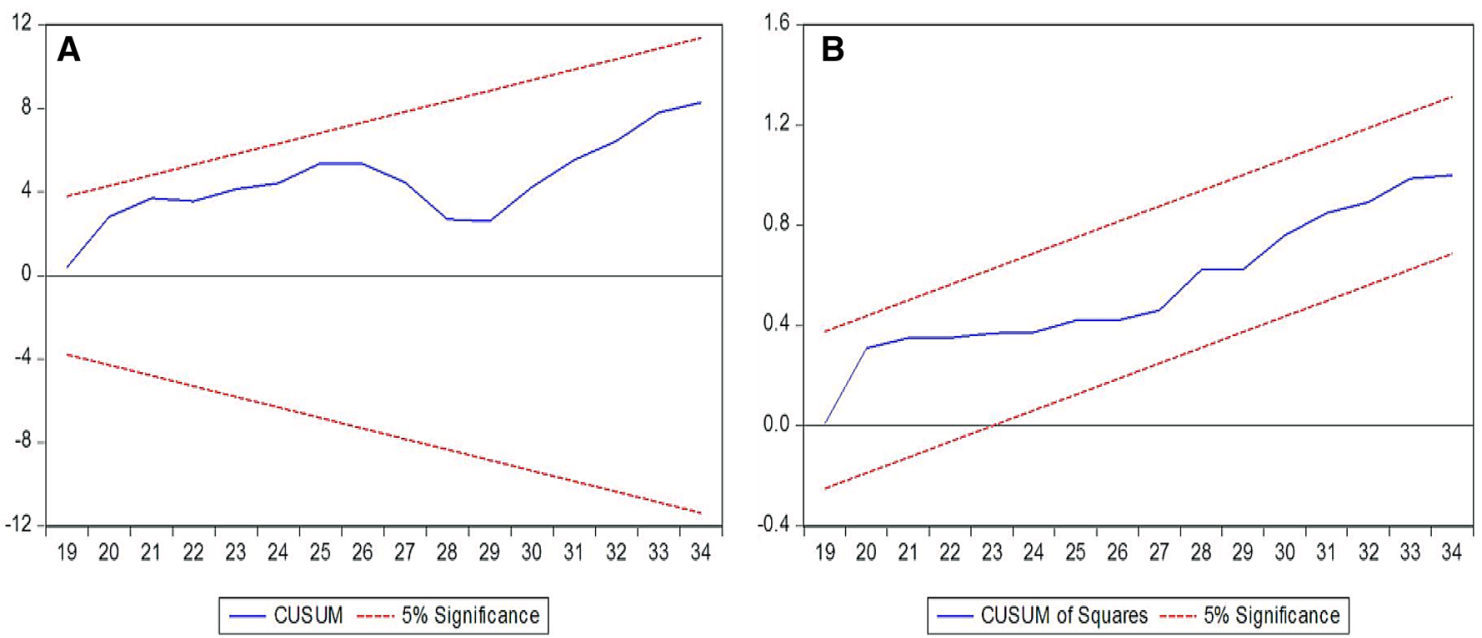

Fig. 6 a Cumulative sum of recursive residual and $\mathbf{b}$ cumulative sum of square of residual recursive (model 2)
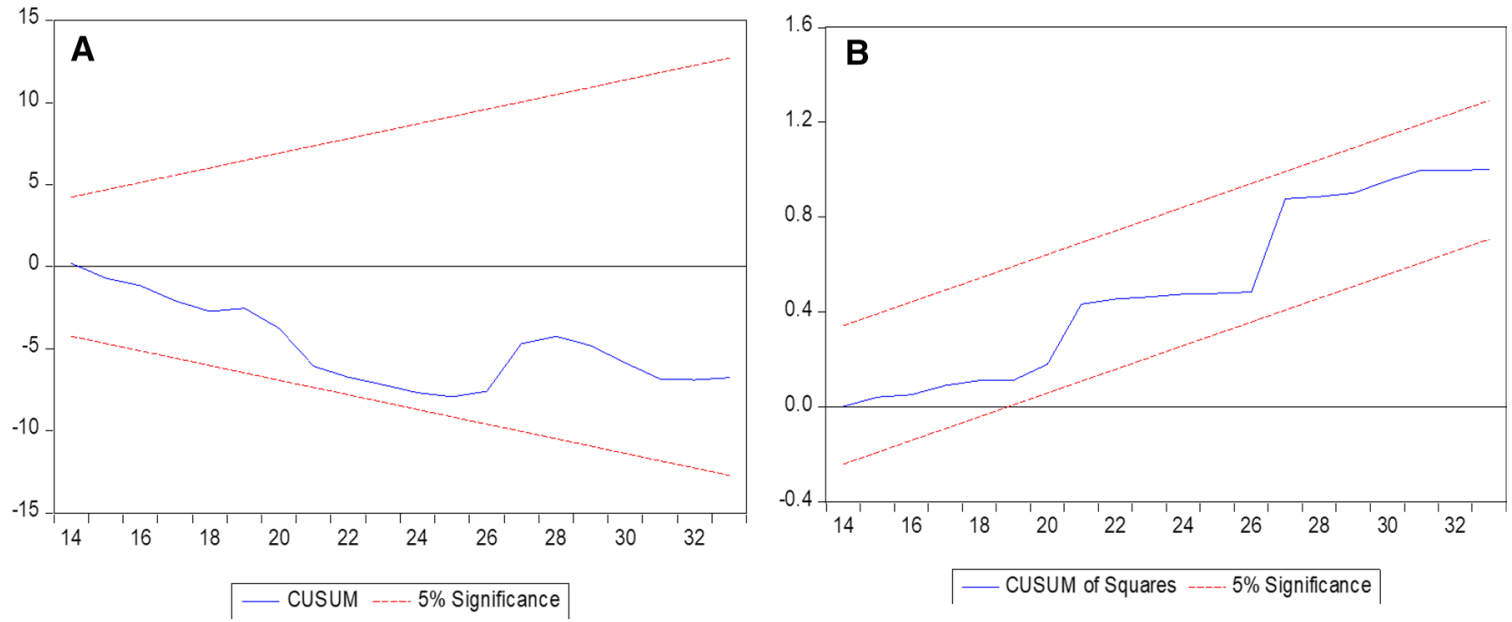

Fig. 7 a Cumulative sum of recursive residual and $\mathbf{b}$ cumulative sum of square of residual recursive (model 3)

\section{SN Applied Sciences}

A SPRINGER NATURE journal 
Table 2 Descriptive statistics of the $\mathrm{CO}_{2}$ emission function

\begin{tabular}{lllllll}
\hline & $\mathrm{CO}_{2}$ & Gov & FDI & GDP & Pop & Indu \\
\hline Mean & 0.767641 & 0.430412 & 1.008421 & 2.041709 & 2.427890 & 21.26865 \\
Median & 0.766580 & 0.440972 & 0.728144 & 2.147733 & 2.237086 & 21.59126 \\
Maximum & 0.991030 & 0.546296 & 3.668323 & 5.478160 & 3.340328 & 25.52832 \\
Minimum & 0.480295 & 0.270833 & 0.178192 & -1.449514 & 1.954080 & 17.94227 \\
SD & 0.150156 & 0.056716 & 0.825654 & 1.733693 & 0.440734 & 1.603583 \\
Jarque-Bera & 2.270183 & 2.298319 & 39.75062 & 0.405059 & 4.623295 & 1.826964 \\
Probability & 0.321393 & 0.316903 & 0.198320 & 0.816662 & 0.099098 & 0.401125 \\
Observations & 34 & 34 & 34 & 34 & 34 & 34 \\
\hline
\end{tabular}

Table 3 Estimation of autoregressive distributed lag (ARDL)-based coefficient value: dependent variable is $\mathrm{CO}_{2}$ emission

\begin{tabular}{lrlrl}
\hline $\begin{array}{l}\text { Explanatory } \\
\text { variables }\end{array}$ & Coefficient & Standard error & T-statistic & $P$ value \\
\hline Gov & -0.180674 & 0.127906 & -1.412558 & 0.1758 \\
Gov $(-1)$ & -0.401868 & 0.148584 & -2.704659 & 0.0150 \\
FDI & 0.007319 & 0.007768 & 0.942209 & 0.3593 \\
FDI (-1) & -0.004273 & 0.009205 & -0.464180 & 0.6484 \\
FDI (-2) & 0.013622 & 0.007105 & 1.917071 & 0.0722 \\
GDP & 0.000390 & 0.001938 & 0.201077 & 0.8430 \\
GDP (-1) & 0.001405 & 0.002067 & 0.679666 & 0.5059 \\
GDP (-2) & 0.007325 & 0.002029 & 3.610262 & 0.0022 \\
Pop & 0.873530 & 0.293499 & 2.976264 & 0.0085 \\
Pop (-1) & 2.229252 & 0.610252 & 3.653006 & 0.0020 \\
Pop (-2) & 1.652295 & 0.365830 & 4.516563 & 0.0003 \\
Indu & 0.002693 & 0.002234 & 1.205175 & 0.2446 \\
Indu (-1) & 0.007359 & 0.002314 & 3.179981 & 0.0055 \\
C & 1.826834 & 0.291249 & 6.272420 & 0.0000 \\
\hline
\end{tabular}

$R^{2}=90.959501$

Adjusted- $R^{2}=50.913216$

F-statistic $=23.8653[0.000]$

indicating that the model is stable; if any error creates the hurdle in the model from its equilibrium path, it will converge toward equilibrium with the speed of $39 \%$ adjustment of disturbance in one year. Only Pop has shown a significant and positive relationship with $\mathrm{CO}_{2}$ emission for the short-term period. It means as population increases, this will cause an increase in $\mathrm{CO}_{2}$ emission, while all independent variables have shown a positive and significant association with the $\mathrm{CO}_{2}$ emission for the long-term period. The value of $\mathrm{F}$-statistic is 23.865 . It indicates that the model is a good fit. The value of $R^{2}$ indicates that the $95 \%$ variation in $\mathrm{CO}_{2}$ is explained by the modeled variance. The single unit increase in $\mathrm{FDI}$ that brings 0.0174 unit changes inside $\mathrm{CO}_{2}$ emission. Whether FDI found to be positive to increase $\mathrm{CO}_{2}$ emission in the Pakistan. Similarly, the results of the shortterm period indicate the consistent sign of the coefficient in the model with the long-term period.
The results revealed that the synchronicity of the positive and significant relationship between $\mathrm{FDI}$ and $\mathrm{CO}_{2}$ makes the strategies to reduce the carbon emission in the environment. Such policies and strategies would helpful for the regulation and enhance the relation between FDI and the environment. The result also shows that such policies create links for the reduction in the $\mathrm{CO}_{2}$ emission with regulation of FDI and GDP environment link. Similarly, the ARDL investigation depicts that per capita GDP has the positive link with the $\mathrm{CO}_{2}$ emission. The coefficient value of the per capita GDP is found to be significant with a value of 0.004 .

The results also show that a one percent increase (decrease) in GDP will 0.004 percent increase (decrease) in $\mathrm{CO}_{2}$ emission. In the detailed investigation, it is stated that this outcome is supporting the results observed [39, $40,22]$. These investigated studies show that that the per capita GDP is directly linked with $\mathrm{CO}_{2}$ emission that boost toward the environmental degradation. Figure 8 a reveals that the trend of the $\mathrm{CO}_{2}$ emission is found to be increased with a rate of 0.476 metric tons per capita. $R^{2}$ value is 0.866 observed during the investigated period from 1984 to 2017. After further investigation, it is stated that $\mathrm{CO}_{2}$ emission decreased from 2007 to 2017. There is likely due to improvement and development of the green belt in Pakistan. The GDP per capita was stable during this span. Figure $8 \mathrm{~b}$ also shows the percentage change of the $\mathrm{CO}_{2}$ emission inter-annually. The high change was observed in the year of 1995 and 2003. In the detailed examination, it is stated that per capita GDP in the same years increased. This shows the significant positive relationship of the $\mathrm{CO}_{2}$ emission and per capita GDP.

\subsection{Impact on $\mathrm{NO}_{x}$ emission}

\subsubsection{Descriptive statistics}

Table 4 represents the descriptive statics values of the $\mathrm{NO}_{x}$ emission function. The results revealed that the probability value of all variables is greater than 0.05 , which shows that the all the data in the model 2 are found to be normally 

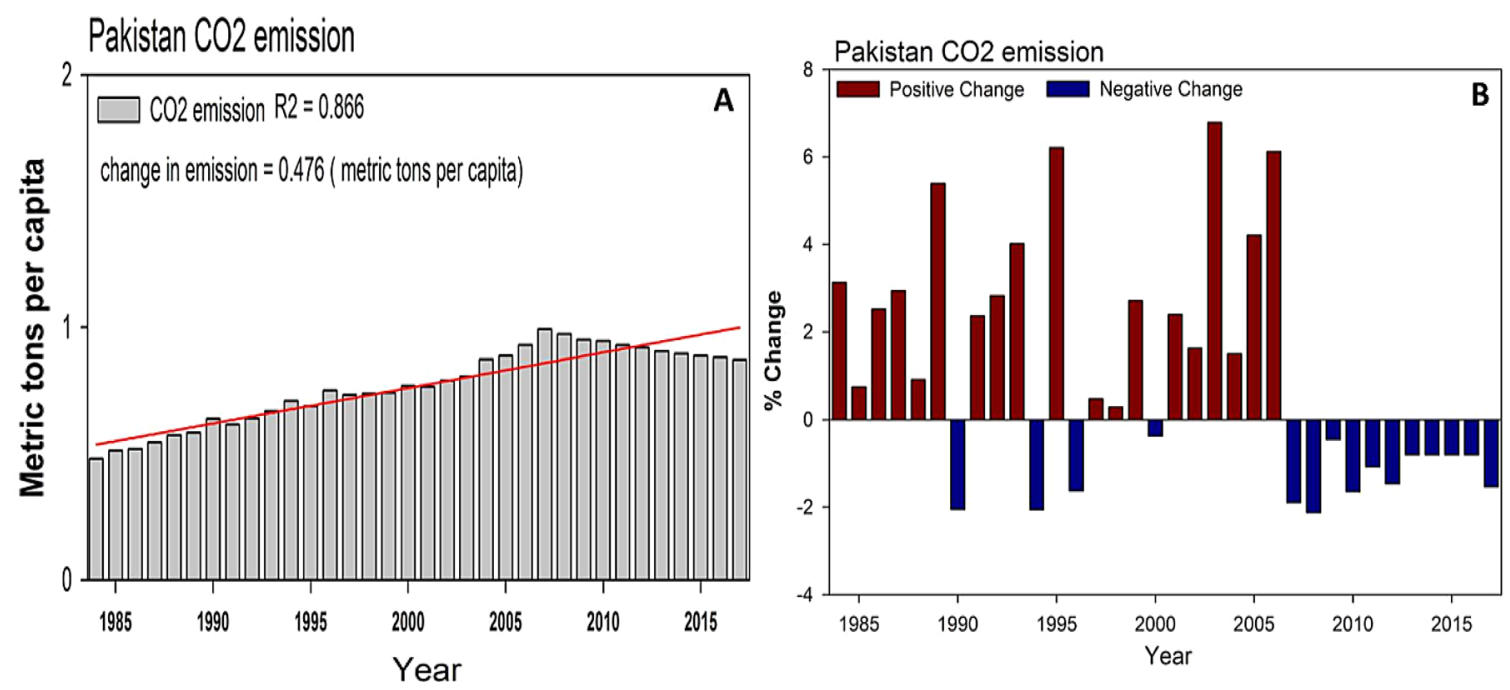

Fig. 8 The $\mathrm{CO}_{2}$ emission trend a total change in Pakistan $\mathrm{CO}_{2}$ emission and $\mathbf{b} \%$ change in Pakistan $\mathrm{CO}_{2}$ emission

Table 4 Descriptive statistics of the $\mathrm{NO}_{x}$ emission function

\begin{tabular}{llllllll}
\hline & $\mathrm{NO}_{x}$ & Gov & Tran & GDP & Pop & FDI & Indu \\
\hline Mean & 11.88029 & 0.430412 & 52.25380 & 2.041709 & 2.427890 & 23.36896 & 21.26865 \\
Median & 12.00247 & 0.440972 & 54.15880 & 2.147733 & 2.237086 & 24.21259 & 21.59126 \\
Maximum & 13.98814 & 0.546296 & 71.22066 & 5.478160 & 3.340328 & 29.78608 & 25.52832 \\
Minimum & 7.931114 & 0.270833 & 34.57587 & -1.449514 & 1.954080 & 15.38607 & 17.94227 \\
SD & 1.380649 & 0.056716 & 10.48349 & 1.733693 & 0.440734 & 4.151071 & 1.603583 \\
Jarque-Bera & 8.223623 & 2.298319 & 1.246479 & 0.405059 & 4.623295 & 2.359601 & 1.826964 \\
Probability & 0.106378 & 0.316903 & 0.536204 & 0.816662 & 0.099098 & 0.307340 & 0.401125 \\
Observations & 34 & 34 & 34 & 34 & 34 & 34 & 34 \\
\hline
\end{tabular}

distributed. After the detailed investigation, it is stated that the probability values of the selected variables in the model 2 included: $\mathrm{NO}_{x}(0.106)$, the Gov (0.317), GDP (0.816), Tran (0.536), Pop (0.099), FDI (0.307) and Indu (0.402).

The minimum values were for $\mathrm{NO}_{x}(7.931)$, the Gov (0.271), Tran (34.57), GDP (-1.449), FDI (15.39), Pop (1.955) and Indu (17.94). The maximum value of Tran is 71.22. The observed maximum values included: $\mathrm{NO}_{x}(13.988)$, the Gov (0.546), FDI (3.66), Tran (71.22), GDP (5.478), FDI (29.78), Pop (3.341) and Indu (25.52).

\subsubsection{Autoregressive distributed lag (ARDL): dependent variable is $\mathrm{NO}_{x}$ emission}

The results of ARDL for model 2 are reported in Table 5 . The value of the error correction model term is $\beta=0.361$ (0.0053), indicating that the model is stable; if any error disturbs the model from its equilibrium path, it will converge toward equilibrium with the speed of $36 \%$ adjustment of disturbance in one year. The results revealed that governance shows a significant and negative association with the emission of nitrogen oxide $\left(\mathrm{NO}_{x}\right)$ for the shortterm period. It means as governance improves, the emission of $\mathrm{NO}_{x}$ will reduce. However, all modeled variables have a positive and significant association with the $\mathrm{NO}_{x}$ emission in the long-term period. The value of $F$-statistic is 30.556. It indicates that the model is a good fit. The value of $R^{2}$ indicates that the $96 \%$ variation in $\mathrm{NO}_{x}$ is explained by the modeled variance.

The results also show the negative relationship between Indu and $\mathrm{NO}_{x}$ emission. The coefficient value shows the long-term relationship of the $\mathrm{NO}_{x}$ emission and Indu. With the increase in the pressure of the Indu, the $\mathrm{NO}_{x}$ emission will increase in the environment that leads toward the environmental degradation. The single unit increase within Indu will result in 0.5012 unit reduction in $\mathrm{NO}_{x}$ release. Similarly, Tran and $\mathrm{NO}_{x}$ also show the positive and significant relationship. One unit increase in Tran that will bring the 0.0563 unit increase in $\mathrm{NO}_{x}$ emission. The coefficient value of the Tran is found to be significant with value 0.0808 . This is likely due to increase in the number of the vehicles. Over the span of the last two decades, the 
Table 5 Estimation of autoregressive distributed lag (ARDL)-based coefficient value: dependent variable is $\mathrm{NO}_{x}$ emission

\begin{tabular}{lrcrl}
\hline $\begin{array}{l}\text { Explanatory } \\
\text { variables }\end{array}$ & Coefficient & Standard error & $T$-statistic & $P$ value \\
\hline $\mathrm{NO}_{x}(-1)$ & 0.360701 & 0.111798 & 3.226372 & 0.0053 \\
Gov & -3.236764 & 1.736471 & -1.863990 & 0.0808 \\
Tran & 0.008891 & 0.014746 & 0.602914 & 0.5550 \\
Tran $(-1)$ & 0.030639 & 0.016754 & 1.828687 & 0.0861 \\
Tran $(-2)$ & 0.014240 & 0.013088 & 1.088023 & 0.2927 \\
GDP & 0.052579 & 0.048215 & 1.090522 & 0.2916 \\
GDP $(-1)$ & 0.116074 & 0.049826 & 2.329583 & 0.0333 \\
GDP $(-2)$ & 0.126882 & 0.043349 & 2.926986 & 0.0099 \\
Pop & 9.365965 & 6.426393 & 1.457422 & 0.1643 \\
Pop $(-1)$ & 26.74763 & 10.94648 & 2.443492 & 0.0265 \\
Pop $(-2)$ & 18.49435 & 5.094050 & 3.630579 & 0.0022 \\
FDI & 0.023141 & 0.024009 & 0.963847 & 0.3495 \\
Indu & 0.061708 & 0.053710 & 1.148910 & 0.2675 \\
Indu $(-1)$ & 0.109765 & 0.048977 & 2.241148 & 0.0396 \\
Indu (-2) & 0.149011 & 0.049441 & 3.013908 & 0.0082 \\
C & 17.21334 & 3.229184 & 5.330552 & 0.0001 \\
\hline
\end{tabular}

$R^{2}=0.966271$

Adjusted $-R^{2}=0.934650$

F-statistic $=30.55769[0.000]$

number of motor vehicles has risen from 2.71 million to nearly 9.08 million. The highest increase is found in a twostroke engine and diesel vehicles [41]. With the increase in the number of the vehicles, the emission rate of the $\mathrm{NO}_{x}$ is $11 \%$ increasing in Pakistan [42]. Motor vehicles release around 90 percent of the total hydrocarbons, $\mathrm{NO}_{x}$ and $\mathrm{CO}_{x}$ in Pakistan. The basic cause of the $\mathrm{NO}_{x}$ emission is the number of the vehicles. $\mathrm{NO}_{x}$ is produced when nitrogen and oxides in the environment combine at high temperature. So, the high amount of the nitrogen and oxygen release in the atmosphere increases the $\mathrm{NO}_{x}$ emission [16]. The number of the vehicles is directly linked with the population. With the increase in the population pressure, the number of the vehicles is found to be positively significant. Therefore, Pop and $\mathrm{NO}_{x}$ emission show the positive and long-term relationship. The one unit increase in POP will increase the 1.7405 unit increase in $\mathrm{NO}_{x}$. Furthermore, GDP and $\mathrm{NO}_{x}$ also show the positive long-term relationship. The single unit increase in per capita GDP will bring 0.4623 unit changes in $\mathrm{NO}_{x}$ emission.

Figure 9a reveals that the trend of the $\mathrm{NO}_{x}$ emission increased with a rate of 4.11 metric tons per capita. $R^{2}$ value was 0.761 during the investigated period of 34 years from 1984 to 2017. After detailed examination, it is stated that $\mathrm{NO}_{x}$ emission increased from 1996 to 2017. There is likely due to the increase in the number of the vehicles and population pressure. Tran and Pop increased during this investigated period. Figure $9 \mathrm{~b}$ also shows the percentage change in the $\mathrm{NO}_{x}$ emission inter-annually. The high change was observed in the year of 1996 and 2001. In the detailed examination, it is stated that Pop and Tran in the same years increased. This shows the a significant positive relationship between the $\mathrm{NO}_{x}$ emission and Pop and Tran

\subsection{Impact on deforestation}

\subsubsection{Descriptive statistics}

Table 6 depicts the descriptive statics values of the DEF function. The results display that the probability value
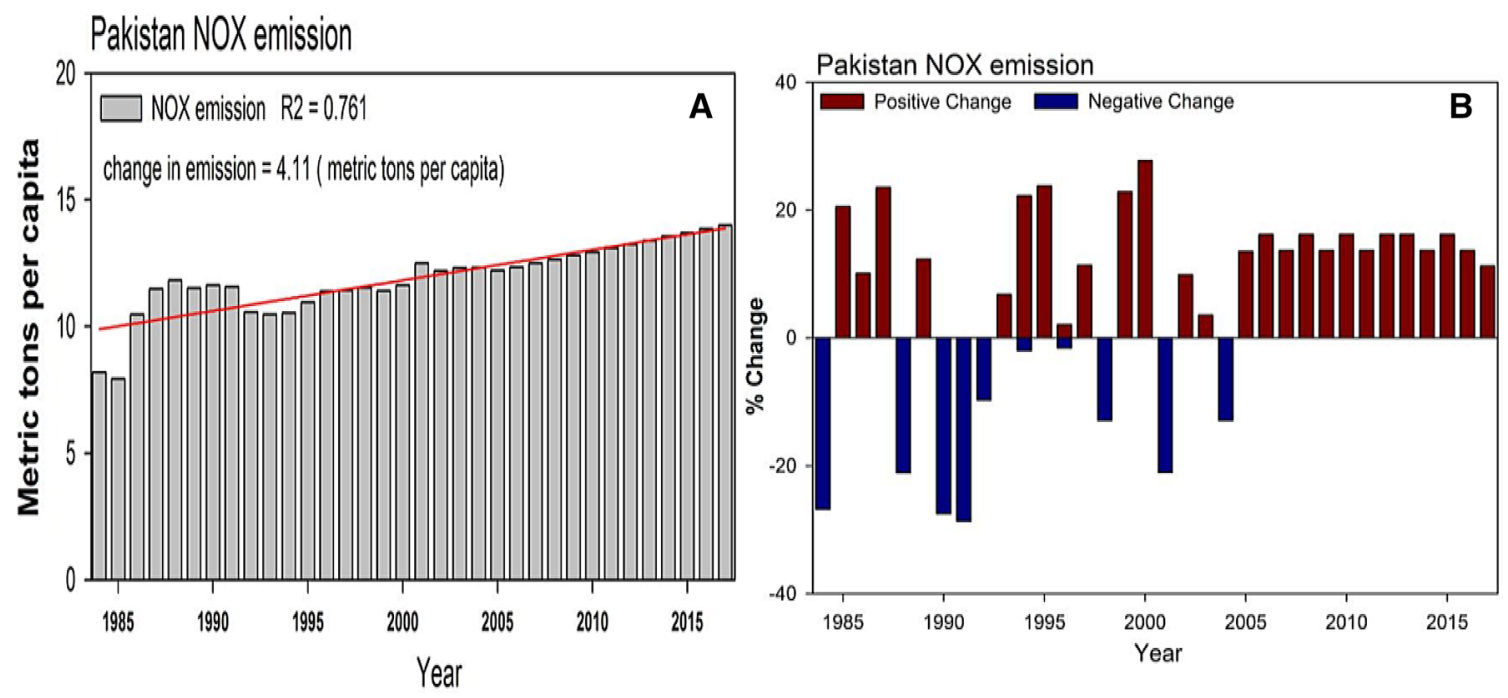

Fig. 9 Show the $\mathrm{NO}_{x}$ emission trend a total change in Pakistan $\mathrm{NO}_{x}$ emission and $\mathbf{b} \%$ change in Pakistan $\mathrm{NO}_{x}$ emission 
Table 6 Descriptive statistics of the DEF function

\begin{tabular}{llllllll}
\hline & DEF & Gov & Indu & FDI & Pop & Urbn & AL \\
\hline Mean & 0.215026 & 0.430412 & 21.26865 & 1.008421 & 2.427890 & 3.365917 & 46.87091 \\
Median & 0.215091 & 0.440972 & 21.59126 & 0.728144 & 2.237086 & 3.237386 & 46.78160 \\
Maximum & 0.318424 & 0.546296 & 25.52832 & 3.668323 & 3.340328 & 4.175389 & 48.64570 \\
Minimum & 0.121970 & 0.270833 & 17.94227 & 0.178192 & 1.954080 & 3.015060 & 45.66988 \\
SD & 0.044283 & 0.056716 & 1.603583 & 0.825654 & 0.440734 & 0.353832 & 0.798487 \\
Jarque-Bera & 0.208646 & 2.298319 & 1.826964 & 39.75062 & 4.623295 & 7.397627 & 1.050225 \\
Probability & 0.900934 & 0.316903 & 0.401125 & 0.198320 & 0.099098 & 0.204753 & 0.591489 \\
Observations & 34 & 34 & 34 & 34 & 34 & 34 & 34 \\
\hline
\end{tabular}

of all variables is greater than 0.05 , which indicated that the data are normally distributed. After the thorough and detailed study of the 34-year span, it is stated that the probability values of the selected variables included: DEF (0.901), the Gov (0.317), Indu (0.401), FDI (0.198), Urbn (0.205), Pop (0.099) and AL (0.592). The minimum values for DEF (0.121), the Gov (0.270), Indu (17.94), FDI (0.178), Urbn (3.017), Pop (1.955) and AL (45.669). The maximum value of the $A L$ is 48.65 . The observed maximum values included: DEF (0.318), the Gov (0.546), Indu (25.52), FDI (3.66), Pop (3.341), Urbn ( 4.176) and AL (48.646).

\subsubsection{Autoregressive distributed lag (ARDL): dependant variable is DEF}

The results of ARDL for model 3 are reported in Table 7. The value of error correction model term is $\beta=0.261$ (0.004), indicating that the model is stable; if any error disturbs the model from its equilibrium path, it will converge toward equilibrium with the speed of $26 \%$ adjustment of disturbance in 1 year. The results revealed that governance has a significant and negative relationship with deforestation for the short-term period. It means good governance reduces the deforestation. The good governance makes the good polices for the reduction in the deforestation. Furthermore, the rich peoples are also involved in the cutting and selling of the plants like concept of timber mafia. This is generally likely due to the lack of the implementation of the forest management techniques and laws. This hurdle in the implementation of the political instability and bad governance. Therefore, governance is directly linked with the deforestation.

The results indicate that the rural population has negligible impact on environmental degradation in the short run as well as in the long run, while urban population has a significant and positive association with environmental degradation. The result reveals that as urban population (urbanization) increases, it will increase the $\mathrm{CO}_{2}$ emission which increases environment degradation in short-run and long-run periods ( $\beta=0.0078$, prob. 0.00006 in the short run, while in the long run $\beta=0.102439$, prob. 0.0009 ).

Similarly, deforestation has significant positive associations with environmental degradation in the short-run as well as in long-run period $\beta=0.028134$ prob. 0.00001 , in the short-run period, while in the long run $\beta=0.272315$, prob. 0.0001 (Table 8). The results of CointEq $(-1)$ indicate
Table 7 Estimation of autoregressive distributed lag (ARDL)-based coefficient value: dependent variable is DEF

\begin{tabular}{|c|c|c|c|c|}
\hline Explanatory variables & Coefficient & Standard error & $T$-statistic & $P$ value \\
\hline $\operatorname{DEF}(-11)$ & 20.260510 & 20.123280 & 2.113157 & 0.00337 \\
\hline Gov & -0.319702 & 0.182837 & -1.748560 & 0.0957 \\
\hline Indu & -0.011025 & 0.005186 & -2.125949 & 0.0462 \\
\hline Indu $(-1)$ & -0.016861 & 0.005547 & -3.039477 & 0.0065 \\
\hline FDI & 0.010216 & 0.015666 & 0.652117 & 0.5218 \\
\hline FDI $(-1)$ & -0.035393 & 0.020035 & -1.766567 & 0.0926 \\
\hline FDI $(-2)$ & 0.022004 & 0.015164 & 1.451079 & 0.1623 \\
\hline Pop & 0.163964 & 0.062045 & 2.642666 & 0.0156 \\
\hline Urbn & -0.168046 & 0.087073 & -1.929949 & 0.0679 \\
\hline AL & -0.003566 & 0.012452 & -0.286342 & 0.7776 \\
\hline C & 1.257491 & 0.713018 & 1.763616 & 0.0931 \\
\hline
\end{tabular}

$R^{2}=0.716869$

Adjusted- $R^{2}=0.575303$

F-statistic $=5.063865[0.001]$ 
Table 8 Estimation of autoregressive distributed lag (ARDL)-based coefficient value: dependent variable is $\mathrm{CO}_{2}$ emission with deforestation, rural and urban population

\begin{tabular}{|c|c|c|c|c|}
\hline \multicolumn{5}{|c|}{ ARDL cointegrating and long-run form } \\
\hline \multicolumn{5}{|c|}{ Dependent variable: $\mathrm{CO}_{2}$} \\
\hline Variable & Coefficient & Std. error & $t$-statistic & Prob. \\
\hline \multicolumn{5}{|l|}{ Cointegrating form } \\
\hline$D(\mathrm{RP})$ & -0.000000 & 0.000000 & -0.472748 & 0.6418 \\
\hline$D(\mathrm{UP})$ & 0.078394 & 0.019056 & 4.113960 & 0.0006 \\
\hline$D$ (Deforestation) & 0.028134 & 0.0043 & 6.542790 & 0.0001 \\
\hline CointEq(-1) & -0.765274 & 0.188551 & -4.058707 & 0.0007 \\
\hline \multicolumn{5}{|c|}{ Long-run coefficients } \\
\hline $\mathrm{RP}$ & -0.000000 & 0.000000 & -0.453429 & 0.6554 \\
\hline UP & 0.102439 & 0.026037 & 3.934319 & 0.0009 \\
\hline Deforestation & 0.272315 & 0.052564 & 5.180636 & 0.0004 \\
\hline C & -3.399979 & 2.064948 & -1.646520 & 0.1161 \\
\hline
\end{tabular}

that the model is stable, if any shock causes to deviate the model from its trend growth path, it will come back to the equilibrium path at the speed of $76 \%$ adjustment in one year and the remaining will settle accordingly.

Moreover, industrialization (Indu) has a positive and significant association with DEF. It means as industrialization increases, DEF will also increase. The single unit increase in Indu brings the 0.03322 unit increase in the DEF. Industrialization increases the human-based anthropogenic activities on the earth. These activities included the overconsumption and overexploitation that cause the air pollution in the environment. Such mechanism leads toward the deforestation. With the increase in the population pressure on earth, the human-based anthropogenic activity increases that make the positive relationship between Pop and DEF. Similarly, in the short-term period, population has a positive and significant association with DEF. While urbanization has a negative and significant association with DEF. However, in the long-term period all modeled variables found a significant association with the DEF. The value of $F$-statistic is 5.064. It indicates that the model is a good fit. The value of $R^{2}$ indicates that the $71 \%$ variation in $\mathrm{DEF}$ is explained by the modeled variance.

Figure 10a reveals that the trend of the DEF decreased with a rate of $-0.0442 . R^{2}$ value was 0.090 observed during the investigated period of 34 years from 1984 to 2017. After detailed examination, it is stated that DEF increased from 1984 to 1994 . There is likely due to increase in the population pressure and anthropogenic activities. Urbn and Pop increased during this investigated period. Figure $10 \mathrm{~b}$ also shows the percentage change in the DEF inter-annually. The high change was observed in the year of 1985 and 2010. In the detailed examination, it is stated that Indu, Pop and Urbn in the same years increased. Therefore, this shows the significant positive relationship of DEF and Pop, Urbn and Indu. In the detailed examination, it is observed that the increase in the deforestation in the year of 2010 was due to heavy flood in Pakistan [43]. Kirsch et al. [21] supported this result that the severe flood of 2010 affected the land use pattern in Pakistan. Therefore, land use pattern decreased during this high level deforestation positive change

The current empirical study found negative and significant cointegration among governance and environmental degradation in the long run, which suggests that as governance improves, environmental degradation will reduce. Therefore, sustainable development can be achieved with the help of good environmental governance. So this study showed that policies and plans should be devised to improve governance in order to achieve a good quality
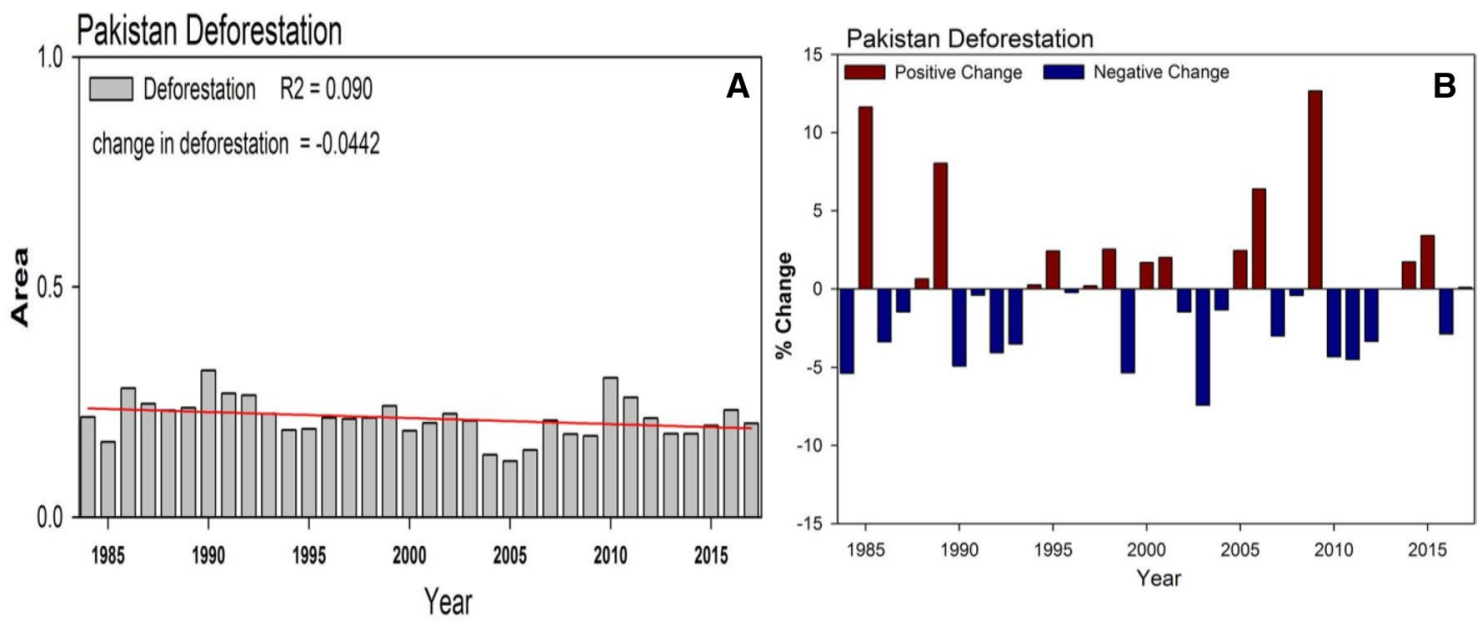

Fig. 10 The trend of the deforestation area $\mathbf{a}$ total change in Pakistan deforestation and $\mathbf{b} \%$ change in Pakistan deforestation 
of the environment. Shaari et al. [44] also claimed that FDI has positive cointegration with environmental degradation; as FDI increases, it will also increase environmental degradation. Results are indicating that FDI leads to the emission of greenhouse gases that causes poor quality of the environment. Therefore, policymakers of the host country should have the knowledge of the threshold for peak inflow of FDI to have a good balance between environment and FDI growth $[19,21]$.

Moreover, the study found a positive and significant association between economic growth and environmental degradation, so this study suggests that the government should devise the policies for green growth rather than economic growth. This study also found that population growth has a positive and significant relationship with environmental degradation. The results of this study are consistent with the Malthus theory of population; the findings suggest the government should educate its people to focus on the quality of children rather than quantity. The government should also develop policies to control human activities regarding the consumption of natural resources to control environmental degradation. This investigation also found that industrialization increases environmental degradation, but no doubt the developed economies made rapid development after the industrial revolution, which recommends that industrialization is a prerequisite of economic growth. So the government should develop policies, not to control industrialization, but for the emission of greenhouse gases from industrialization. The government should impose a carbon tax on industries to regulate the emission of greenhouse gases and the government design policies to promote the green industry.

\section{Conclusion}

In the current research, an impact assessment of the socioeconomic factors is investigated on different dimensions of environmental degradation using the statistical models I, 2 and 3. The study found a negative and significant impact on environmental degradation in all three models. Results indicated that as governance improves, it will cause to reduce $\mathrm{CO}_{2}$ emission, $\mathrm{NO}_{x}$ emission and deforestation that will improve the quality of the environment. Similarly, the analysis incorporated that FDI, per capita GDP, industrialization and the total population have a positive and significant impact on environmental degradation in the long run; as FDI, per capita GDP and total population increase, it will cause to increase environmental degradation.

According to the results, the rural population has an insignificant association with environmental degradation, while the urban population has a significant and positive association with environmental degradation. Similarly, agriculture land has an insignificant association with environmental degradation and deforestation has a significant and positive impact on $\mathrm{CO}_{2}$ emission. Results indicated that as deforestation increases, it will increase $\mathrm{CO}_{2}$ emission which will deteriorate the environmental quality. In the future, researchers can utilize other proxies like an ecological footprint to measure environmental degradation. Moreover, in the future quality of institutions can be taken as the moderator to strengthen the favorable results and weaken the undesired results.

\section{Compliance with ethical standards}

Conflict of interest The authors declare that they have no conflict of interest.

\section{Appendix}

See Table 9. 
Table 9 Appendix of variables and its description

\begin{tabular}{|c|c|c|}
\hline Variable name & Description & Sources \\
\hline Control of corruption & $\begin{array}{l}\text { Control of corruption captures perceptions of the extent to which public power is exercised for private } \\
\text { gain, including both petty and grand forms of corruption, as well as "capture" of the state by elites } \\
\text { and private interests. Estimate gives the country's score on the aggregate indicator, in units of a } \\
\text { standard normal distribution, i.e., ranging from approximately - } 2.5 \text { to } 2.5\end{array}$ & WDI \\
\hline Government effectiveness & $\begin{array}{l}\text { Government effectiveness captures perceptions of the quality of public services, the quality of the civil } \\
\text { service and the degree of its independence from political pressures, the quality of policy formulation } \\
\text { and implementation, and the credibility of the government's commitment to such policies. Estimate } \\
\text { gives the country's score on the aggregate indicator, in units of a standard normal distribution, i.e., } \\
\text { ranging from approximately - } 2.5 \text { to } 2.5\end{array}$ & WDI \\
\hline $\begin{array}{l}\text { Political stability and } \\
\text { absence of violence/ } \\
\text { terrorism }\end{array}$ & $\begin{array}{l}\text { Political stability and absence of violence/terrorism measures perceptions of the likelihood of political } \\
\text { instability and/or politically-motivated violence, including terrorism. Estimate gives the country's } \\
\text { score on the aggregate indicator, in units of a standard normal distribution, i.e., ranging from } \\
\text { approximately - } 2.5 \text { to } 2.5\end{array}$ & WDI \\
\hline Rule of law & $\begin{array}{l}\text { Rule of law captures perceptions of the extent to which agents have confidence in and abide by the } \\
\text { rules of society, and in particular the quality of contract enforcement, property rights, the police, and } \\
\text { the courts, as well as the likelihood of crime and violence. Estimate gives the country's score on the } \\
\text { aggregate indicator, in units of a standard normal distribution, i.e., ranging from approximately - } 2.5 \\
\text { to } 2.5\end{array}$ & WDI \\
\hline Regulatory quality & $\begin{array}{l}\text { Regulatory quality captures perceptions of the ability of the government to formulate and implement } \\
\text { sound policies and regulations that permit and promote private sector development. Estimate gives } \\
\text { the country's score on the aggregate indicator, in units of a standard normal distribution, i.e., rang- } \\
\text { ing from approximately - } 2.5 \text { to } 2.5\end{array}$ & WDI \\
\hline Regulatory quality & $\begin{array}{l}\text { Regulatory quality captures perceptions of the ability of the government to formulate and implement } \\
\text { sound policies and regulations that permit and promote private sector development. Estimate gives } \\
\text { the country's score on the aggregate indicator, in units of a standard normal distribution, i.e., rang- } \\
\text { ing from approximately - } 2.5 \text { to } 2.5\end{array}$ & WDI \\
\hline Voice and accountability & $\begin{array}{l}\text { Voice and accountability captures perceptions of the extent to which a country's citizens are able to } \\
\text { participate in selecting their government, as well as freedom of expression, freedom of association, } \\
\text { and a free media. Estimate gives the country's score on the aggregate indicator, in units of a stand- } \\
\text { ard normal distribution, i.e., ranging from approximately }-2.5 \text { to } 2.5\end{array}$ & WDI \\
\hline
\end{tabular}

\section{References}

1. Morelli J (2011) Environmental sustainability: a definition for environmental professionals. J Environ Sustain 1(1):2

2. Mastruzzi M, Kraay A, Kaufmann D (2007) Governance matters VI: aggregate and individual governance indicators, 1996-2006. The World Bank, Washington, DC

3. McMichael AJ, Woodruff RE, Hales S (2006) Climate change and human health: present and future risks. The Lancet 367(9513):859-869

4. Li Q, Reuveny R (2006) Democracy and environmental degradation. Int Stud Q 50(4):935-956

5. Rajakumar M, Selvaraj A (2017) Environmental education issues and challenges. Lulu, Raleigh

6. Panayotou T (1993) Empirical tests and policy analysis of environmental degradation at different stages of economic development (No. 992927783402676). International Labour Organization

7. Abbas S, Khan K, Khan AA (2016) REED plus and their impact on Green Economy Development: implication for the sustainable forest development, Swat Valley, HKH region Khyber PakhtunKhwa, Pakistan. Sci Int (Lahore) 28(5):4657-4664

8. IPCC (2012) Third assessment report. Climate change and human health: risks and responses, pp 43-60

9. Abbas S, Hussain MS, Im S, Lee S, Shirazi SA (2018) Urban growth and its effect on temperature trends of Lahore City, Pakistan. J Clim Res 13(3):231-245
10. IPCC (2014) Summary for policymakers in Climate Change 2014: impacts, adaptation, and vulnerability. Part A: global and sectoral aspects. Contribution of Working Group II to the fifth assessment report of the intergovernmental panel on climate change, pp 1-32

11. Abbas S, Shirazi SA, Qureshi S (2018) SWOT analysis for socioecological landscape variation as a precursor to the management of the mountainous Kanshi watershed, Salt Range of Pakistan. Int J Sustain Dev World Ecol 25(4):351-361

12. Government of Pakistan (2017) Pakistan economic survey. The Ministry of Finance, Government of the Pakistan, Islamabad

13. Ullah W, Takaaki N (2016) Climate change vulnerability of Pakistan towards natural disasters: a review. Int J Environ Prot Policy 4(5):1-7

14. World Health Organization (2008) Global health workforce alliance. Pakistan's lady health worker programme: global health workforce alliance. World Health Organization, case study. World Health Organization, Geneva

15. Food FAO (2010) Agriculture Organization of the United Nations, Rome: 2014. The State of the World's Forest Genetic Resources

16. Ghauri B, Lodhi A, Mansha M (2007) Development of baseline (air quality) data in Pakistan. Environ Monit Assess 127(1-3):237-252

17. Martin T, Schwartz DL (2005) Physically distributed learning: adapting and reinterpreting physical environments in the development of fraction concepts. Cogn Sci 29(4):587-625 
18. Ohlsson L (2000) Livelihood conflicts: linking poverty and environment as causes of conflict. Swedish International Development Cooperation Agency (SIDA), Stockholm, p 16

19. To AH, Ha DTT, Nguyen HM, Vo DH (2019) The impact of foreign direct investment on environment degradation: evidence from emerging markets in Asia. Int J Environ Res Public Health 16(9):1636

20. Nguyen DP (2018) The relationship between foreign direct investment, economic growth and environmental pollution in Vietnam: an autoregressive distributed lags approach. Int J Energy Econ Policy 8(5):138

21. Niu S, Ding Y, Niu Y, Li Y, Luo G (2011) Economic growth, energy conservation and emissions reduction: a comparative analysis based on panel data for 8 Asian-Pacific countries. Energy Policy 39(4):2121-2131

22. Yousaf A, Khan H, Erum N, Rasul S (2016) An analysis of foreign aid and environmental degradation in Pakistan is using the ARDL bounds testing technique (1972-2013). Environ Econ $7(1): 16$

23. Masood J, Farooq F, Saeed $\mathrm{M}$ (2015) $\mathrm{CO}_{2}$ and environment change evidence from Pakistan. Rev Econ Dev Stud 1(2):57-72

24. Bhatti Ml, Al-Shanfari H (2017) Econometric analysis of model selection and model testing. Routledge, Abingdon

25. Choi E, Heshmati A, Cho Y (2010) An empirical study of the relationships between $\mathrm{CO}_{2}$ emissions, economic growth and openness. IZA Discussion Paper No. 5304

26. Chen JH, Huang YF (2013) The study of the relationship between carbon dioxide $\left(\mathrm{CO}_{2}\right)$ emission and economic growth. J Int Glob Econ Stud 6(2):45-61

27. Cohen G, Jalles JT, Loungani P, Marto R, Wang G (2019) Decoupling of emissions and GDP: evidence from aggregate and provincial Chinese data. Energy Econ 77:105-118

28. Meyer AL, Van Kooten GC, Wang S (2003) Institutional, social and economic roots of deforestation: a cross-country comparison. Int For Rev 5(1):29-37

29. Kaufmann D, Kraay A, Mastruzzi M (2011) The worldwide governance indicators: methodology and analytical issues. Hague J Rule Law 3(2):220-246

30. Agyeman J, Bullard RD, Evans B (2003) Just sustainabilities: development in an unequal world. MIT Press, Cambridge

31. Granger CW (1988) Some recent development in a concept of causality. J Econom 39(1-2):199-211

32. Ölund Wingqvist $G$, Drakenberg $O$, Slunge $D$, Sjöstedt $M$, Ekbom A (2012) The role of governance for improved environmental outcomes. Swedish Environmental Protection Agency, Report, 6514

33. Al-Marhubi $F$ (2004) The determinants of governance: a crosscountry analysis. Contemp Econ Policy 22(3):394-406

34. Abid M (2016) Impact of economic, financial, and institutional factors on $\mathrm{CO}_{2}$ emissions: evidence from sub-Saharan Africa economies. Util Policy 41:85-94

35. Johansen S, Juselius K (1988) Hypothesis testing for cointegration vectors: with application to the demand for money in Denmark and Finland (No. 88-05)

36. Pesaran MH, Timmermann A (2005) Small sample properties of forecasts from autoregressive models under structural breaks. J Econom 129(1-2):183-217

37. Pesaran MH, Shin Y, Smith RJ (2001) Bounds testing approaches to the analysis of level relationships. J Appl Econom 16(3):289-326

38. Harris R, Sollis R (2003) Applied time series modelling and forecasting. Wiley, Chichester

39. Hossain $\mathrm{S}$ (2012) An econometric analysis for $\mathrm{CO}_{2}$ emissions, Energy Consumption, Economic Growth, Foreign Trade and Urbanization of Japan. Low Carbon Econ 33(4):92-105

40. Jalil A, Mahmud SF (2009) Environment Kuznets curve for $\mathrm{CO}_{2}$ emissions: a cointegration analysis. Energy Policy 37(12):5167-5172

41. Colbeck I, Nasir ZA, Ali Z (2010) The state of ambient air quality in Pakistan-a review. Environ Sci Pollut Res 17(1):49-63

42. Khokhar MF, Mehdi H, Abbas Z, Javed Z (2016) Temporal assessment of $\mathrm{NO}_{2}$ pollution levels in urban centers of Pakistan by employing ground-based and satellite observations. Aerosol Air Qual Res 16(8):1854-1867

43. Pakistan Metrological Department (2018) Government of Pakistan. https://www.wmo.int/pages/prog/www/tcp/documents/ PTC-45_DOC4.2.2_CountryReport_Pakistan.pdf

44. Shaari MS, Hussain NE, Abdullah H, Kamil S (2014) Relationship among Foreign direct investment, economic growth and $\mathrm{CO}_{2}$ emission: a panel data analysis. Int J Energy Econ Policy 4(4):706-715

Publisher's Note Springer Nature remains neutral with regard to jurisdictional claims in published maps and institutional affiliations. 